\title{
Total cost comparison of standard antenatal care with a weight gain restriction programme for obese pregnant women
}

Nicholas DeKeyser, Ann Josefsson, Wiktor Monfils-Gustavsson, Ing-Marie Claesson, Per Carlsson, Adam Sydsjö and Gunilla Sydsjö

\section{Linköping University Post Print}

N.B.: When citing this work, cite the original article.

Original Publication:

Nicholas DeKeyser, Ann Josefsson, Wiktor Monfils-Gustavsson, Ing-Marie Claesson, Per Carlsson, Adam Sydsjö and Gunilla Sydsjö, Total cost comparison of standard antenatal care with a weight gain restriction programme for obese pregnant women, 2011, Public Health, (125), 5, 311-317.

http://dx.doi.org/10.1016/j.puhe.2011.02.004

Copyright: WB Saunders

http://www.elsevier.com/

Postprint available at: Linköping University Electronic Press http://urn.kb.se/resolve?urn=urn:nbn:se:liu:diva-69914 


\title{
Total cost comparison of standard antenatal care to a weight gain restriction program for obese pregnant women
}

$\mathrm{N}$ de Keyser MD *, A Josefsson MD, PHD *, W Gustafsson Monfils MD*, I-M

Claesson MA*, Per Carlsson PHD ${ }^{\dagger}$, A Sydsjö MD, PHD* G Sydsjö PHD*

*Division of Obstetrics and Gynaecology, Dept. of Clinical and Experimental

Medicine.

${ }^{\dagger}$ Center for Medical Technology Assessment, Department of Medical and Health

Sciences

Faculty of Health Sciences, Linköping University

SE-581 85 Linköping, Sweden

Short running title: Weight gain restriction cost for pregnant women

Correspondence to: Prof. Gunilla Sydsjö, Department of Obstetrics and

Gynaecology

University Hospital, SE-581 85 Linköping, Sweden.

Phone +461322 2000 Fax +4613148156 e-mail: Gunilla.Sydsjo@lio.se

\begin{abstract}
Objective: To perform a cost-comparison of a weight gain restriction program for obese pregnant women compared with standard antenatal care and also to identify if there were differences in health-care costs within the intervention group related to degree of gestational weight gain or degree of initial obesity.

Study Design: A clinical case-control intervention study at Antenatal care clinics in the southeast region of Sweden.
\end{abstract}


Method: In total 155 women in an intervention group attempted to restrict gestational weight gain to less than $7 \mathrm{~kg}$. The control group was comprised of 193 women. Mean costs during pregnancy, delivery and the neonatal period were compared with costs of standard care. Costs converted from Swedish Crowns (SEK) to EURO.

Results: The health care cost during pregnancy was lower in the intervention group. There was no significant difference in total health care costs; that is, the sum of costs during pregnancy, delivery and the neonatal period between the intervention group and the control group. Within the intervention group the subgroup that gained $4.5-$ $9.5 \mathrm{~kg}$ had the lowest costs. The total cost, including the intervention costs, was EURO 1283 more per woman/infant in the intervention group compared to the control group ( $\mathrm{p}=0.025)$. The degree of obesity at inclusion to the program had no bearing on the outcome.

Conclusions: The weight gain restriction program for obese pregnant women was effective in restricting gestational weight gain to less than $7 \mathrm{~kg}$ but had a higher total cost compared to the control group.

Key Words: Pregnancy, Weight restriction, Intervention, Cost-effectiveness

\section{Introduction}

The epidemic of obesity is not confined to a single subset of the world's population, but is spread throughout all races, age groups, sexes and socio-economic classes including pregnant women ${ }^{1-3}$. A Swedish study shows that from 1978 through 2001 the proportion of overweight women in childbearing age has tripled, and obesity in that population has increased five-fold in Sweden ${ }^{4}$. The increase in body mass index (BMI) brings with it an increased risk for complications during pregnancy, delivery and the postpartum period ${ }^{5-9}$. The infant of an obese woman has increased risks for 
antepartum stillbirth, neonatal death, birth defects, and neonatal complications ${ }^{10-14}$. Recent studies show that some of these risks are averted if a woman's pregnancy weight gain is restricted ${ }^{\mathbf{1 5 - 1 7}}$. Few studies have provided quantitative estimations of the related increase in the use of health care services for obese pregnant women. Health care costs in general for obese pregnant women have been studied by Chu et al $2008^{18}$,who found that obesity during pregnancy was associated with significantly more examinations during pregnancy, more obstetrical ultrasonographic examinations and increased use of medication. That study also found that obese women also had more prenatal visits with physicians, a longer hospital stay after delivery, and more telephone calls to the department of obstetrics and gynaecology. Most of the increase in length of stay associated with higher BMI was related to increased rates of caesarean delivery and obesity-related high-risk conditions. Interventions to control excessive pregnancy weight gain are few and have shown poor results ${ }^{19-21}$. Policymakers and healthcare planners are aware that even a small increase in the cost of health care - associated with obesity during pregnancy for the women and later her child - will have substantial economic implications for the future. This makes intervention programs and assessment of efficacy and economic viability of interventions essential. In order to make an informed decision about which interventions to implement, healthcare providers and policy makers must have information on which programs maximize health given ever-present budget constraints. The purpose of this study was to perform a comparison of the total costs during pregnancy, delivery and neonatal period between women in the index group of a weight-gain restriction program for obese pregnant women conducted at the University Hospital of Linköping, Sweden with a cohort given standard antenatal care. 


\section{Methods}

The Swedish antenatal health care system as well as the delivery care reaches almost $100 \%$ of all pregnant women. The antenatal and delivery care is free of charge. At the antenatal care clinics (ACC) healthy pregnant women are recommended to attend the regular antenatal program with seven to nine visits to a midwife, and if needed, extra appointments with an obstetrician and/or with the midwife. In the intervention study pregnancy weight gain was controlled in the intervention group through weekly motivational meetings with a both cognitive and behavioural change approach conducted by a specially trained midwife. All women who accepted to take part in the intervention were invited to 30 minute session every week. The midwife worked according to the following schedule:1) a thorough assessment of the pregnant woman's knowledge of obesity as a risk factor during pregnancy, childbirth and for the child; 2) if the woman lacked sufficient knowledge she was offered the information and given accurate facts; 3) the woman was also informed about the potential consequences of behaviour and cognition associated with eating and food intake; written information was supplied if needed; 4) all successive sessions included weight control and a supportive talk with regards to how to deal with food intake, motivational change of behaviour, how to deal with partner and family, supporting exercises and behavioural pitfalls; 5) all women were also invited to participate in a water-gymnastics program designed for obese women once or twice a week ${ }^{22}$. The target weight gain was $<7 \mathrm{~kg}$. The women in the control group were offered standard antenatal care.

The intervention group consisted of 155 women with a BMI $\geq 30$ chosen consecutively from all pregnant women attending regular antenatal care at the University Hospital of Linköping, Sweden: November 2003 through December 2005. 
Exclusion criteria were: inability to speak and understand Swedish, diagnosed diabetes or diseases related to thyroid function, and current treatment with neuroleptic drugs which excluded 45 women from participation. Thirteen women had an early miscarriage or a legal abortion and were also excluded as well as 29 women who moved out of the catchment's area in early pregnancy. Two hundred and thirty obese women were thus eligible and invited to participate. Out of these, 70 women refrained from participation and five women dropped out during the intervention. Thus a total of 155 obese women $(67.4 \%)$ accepted and completed the intervention. To form the control group women with the same inclusion and exclusion criteria were consecutively invited from the ACCs in two nearby cities during the same time period as inclusion of the intervention participants. Three hundred and eighty-five women were invited to participate, 177 women refrained from participation and 15 women dropped out during the study period. Thus 193 (50.1\%) women accepted and completed their participation as controls. The obese women in the control group attended the routine antenatal care program. All three cities share similar demographics such as age, parity, marital status and smoking. ${ }^{22}$ and lie within the Southeast Region of Sweden.

\section{Costs}

All costs are converted from Swedish Kronor to EURO at a 10:1 ratio.

\section{Cost of the Intervention Program}

A motivational meeting with the midwife cost EURO 82 (national average cost of a 30 minute meeting with a midwife). Each meeting was documented in the patient's journal. The cost of the water-gymnastics pool rental was approximately EURO 60 per hour. Each water-gymnastics session was supervised by a midwife with a concurrent cost of EURO 28 per session. 
Cost of productivity loss resulting from participation in the program was calculated using the mean monthly income in 2005 for all Swedish women (EURO 2210). Fifty percent was added for the employer's contribution to the national social insurance system giving a total of EURO $3315^{23}$. Given that roughly two-thirds of the women in the intervention group were employed at the beginning of the program, we multiplied the total monthly income by $2 / 3$ to reach a sum of EURO 2210. There are approximately 22 working days per month. The hourly cost of productivity loss is therefore calculated by: 3683 / 22 giving a daily income of EURO 100, then divided by eight working hours $(100 / 8)=$ EURO 12.56. Each motivational meeting or watergymnastics session was assumed to take 1.5 hours, including travel time, and thus contributed EURO 19 to the cost of the Program.

The number of motivational meetings attended was obtained from standardized patient journals. The number of water-gymnastics sessions attended was obtained from a sign-in sheet.

\section{Cost for Healthcare}

Hospital costs during pregnancy, delivery and neonatal care of the newborn were calculated using national averages as presented in NordDRG. Diagnosis-Related Group (DRG) uses a system of averaging costs for diagnosis, procedures performed, gender, age, length of hospitalization, and status at discharge to classify patients into categories with similar resource use $\mathrm{e}^{24}$. The following inclusions and assumptions were made when assigning each diagnosis into each DRG:

\section{Costs During Pregnancy:}

Each appointment with a physician, whether outpatient at the hospital or at a public antenatal care clinic cost EURO 297. The cost for a midwife consulting a physician was estimated to be $1 / 3$ the cost of an appointment; that is, EURO 99. An 
appointment with a midwife costs EURO 82. In the event of in-patient care during pregnancy the appropriate DRG costs were assigned.

\section{Costs During Delivery}

The guidelines for the choice of DRG during delivery were: 1) Vaginal delivery, uncomplicated 2) if a vaginal delivery: a) required the use of instrumental aid, b) resulted in a Grade III-IV vaginal rupture, c) resulted in placental retention or d) if there was bleeding $>1000 \mathrm{~mL}$ it was listed as a Vaginal Delivery, complicated 3)

Caesarean Section, uncomplicated and 4) if an acute caesarean section was performed it was listed as a Caesarean Section, complicated.

\section{Costs of Neonatal Care}

The assigned DRG for each case depended on the birth weight and number of diagnoses/complications that were noted in the journal. In the case of a diagnosis of "large for gestational age", "postmature", and "hyperbilirubinemia", the diagnosis was not considered a complication if the infant was not treated in the neonatal ward. An uncomplicated pregnancy, vaginal delivery and a healthy child costs EURO 4400. A short hospitalization during pregnancy, such as might result in the case of an emergency caesarean section and an infant requiring limited hospital care, for example, costs EURO 12000.

Analyses

Mean total healthcare costs and costs during pregnancy, delivery and neonatal care of the intervention group were compared to the control group. Further, the weight-gain subgroups of women who gained under $7 \mathrm{~kg}$ (the target maximum weight gain of the program) and $7 \mathrm{~kg}$ and over were compared. Since weight gain recommendations are a topic of current debate, we further divided the groups as follows: 1) those that gained less than $4.5 \mathrm{~kg}$ during pregnancy 2) those whose gain was within the range $4.5-9.5$ 
$\mathrm{kg}$, and 3) those who gained more than $9.5 \mathrm{~kg}$. Cost variables within each of these subgroups were compared with the control group. Weight gain was calculated using the last registered weight during motivational meeting minus weight at enrolment in the program. Each of these subgroups were further compared to their respective weight-gain interval in the control group to determine if any potential differences were possibly attributable to factors other than weight-gain. Additionally, we compared the outcomes based on the individuals' BMI at admission to the program (stratified into $30-34.9 \mathrm{~kg} / \mathrm{m}^{2}, 35-39.9 \mathrm{~kg} / \mathrm{m}^{2}$ and $\geq 40 \mathrm{~kg} / \mathrm{m} 2$ ) to elucidate any possible effect the degree of obesity had on the results of the program.

\section{Statistical Methods}

Mean total healthcare costs and costs during pregnancy, delivery and neonatal care were compared. Additionally, the cost of the intervention was added to the total costs and compared to the total average cost for a pregnant woman in the control group. The costs were compared using the Student's t-test ${ }^{23}$. All tests were two-tailed and the 95\% confidence intervals (CI) were calculated. All calculations were performed by SPSS v.15.0.

\section{Results}

A brief summary of the results of the intervention program (for more details on obstetrical and neonatal outcome see Claesson et al $2007^{22}$ ).

The mean weight gain for the intervention group $(8.7 \mathrm{~kg})$ was $2.6 \mathrm{~kg}$ less than that of the control group $11.3 \mathrm{~kg}(\mathrm{p}<0.001)$. There were significantly more women in the index group, compared with the women in the control group who gained less than 7 $\mathrm{kg}(\mathrm{p}=.003)$, and there were more nulliparous women in this group, compared with the control group $(\mathrm{p}=.018)$. The women in the index group had a significantly lower BMI at the postnatal check-up, compared with the control group $(\mathrm{p}<.001)$. Neonatal 
outcomes such as birthweight, gestational age and mode of delivery/complications did not differ between the groups. The same held true when the analyses were restricted to women who gained less than $7 \mathrm{~kg}$ during their pregnancies ${ }^{22}$.

\section{Total health care costs}

In each of the intervention and control groups an extremely preterm infant was hospitalized for approximately 90 days. Both cases were excluded from the calculation of neonatal costs, total health care costs, and total cost of health care and intervention. No difference in total health care costs was found. However, the intervention group had a statistically significant lower cost during pregnancy (approximately EURO 348 per woman).

\section{Total cost of health care and intervention}

As seen in Table 1, the per woman intervention cost is EURO 1616. During the 27 months of the intervention program, 155 women participated for a total cost of EURO 250511 . The mean per woman/infant difference in total cost, including intervention cost, was EURO 1283 more for the intervention group compared to the control group $(\mathrm{p}<0.025)$

Intervention sub-groups compared to control group

For sub-group analyses within the intervention group we analyzed the group of women that held their weight-gain to less than $7 \mathrm{~kg}$ (the target maximum weight gain for the intervention group) against all controls, as well as those intervention women who had weight gain $>7 \mathrm{~kg}$ against controls. There was no difference in total costs. Intervention sub-groups $<4.5,4.5-9.5,>9.5 \mathrm{~kg}$ compared to control group Results of the analyses of subgroup "weight gain $<4.5 \mathrm{~kg}$ " were suggestive of an increased cost for neonatal care and total costs (p-values 0.16 and 0.20 respectively) when compared to the control group. However, after excluding the extremely preterm 
Table 1. Average costs in EURO per woman or woman/child pair: Intervention and Control Groups

$\begin{array}{lll}\begin{array}{l}\text { INTERVENTION } \\ (\mathrm{n}=155)\end{array} & \begin{array}{l}\text { CONTROL } \\ (\mathrm{n}=193)\end{array} \\ \text { mean }(\mathrm{SD}) & \text { mean }(\mathrm{SD}) & \text { p-value } 95 \% \mathrm{CI}\end{array}$

\section{HEALTH CARE COSTS}

\section{Pregnancy}

Physician Appointment

Physician Consultation

Midwife Appointment

Hospitalization (DRG)

Total

Delivery

Hospitalization (DRG)

\section{Neonatal Care}

(One child in each group are missing in the analysis)

Hospitalization (DRG)

TOTAL HEALTH CARE COSTS

\section{INTERVENTION COSTS}

Motivational meetings

Productivity losses during meetings

Water gymnastics

Productivity losses

during water gymnastics

Total intervention costs

TOTAL COST OF

HEALTH CARE AND

INTERVENTION (per woman/child pair)
778 (592)

$94(131)$

$658(125)$

169 (619)

$1699(1040)$

2397 (1012)

$(\mathrm{n}=154)$

3187 (4550)

7258 (5117)

1156

248

83

131

1616

$\begin{array}{lll}928(866) & 0.057 & -304 \text { to } 4 \\ 67(104) & 0.039 & 1 \text { to } 53 \\ 713(173) & 0.001 & -86 \text { to }-23 \\ 263(616) & 0.157 & -226 \text { to } 37 \\ 2044(1199) & 0.004 & -582 \text { to }-109\end{array}$

$2302(1039)$

$0.390-122$ to 313

$(\mathrm{n}=192)$

3559 (4732) $\quad 0.885 \quad-1062$ to 917

$7595(5390) \quad 0.556 \quad 785$ 
Table 2. Average costs in EURO per woman or woman/child pair*: Intervention Subgroups $<7 \mathrm{~kg}$ and $\geq 7 \mathrm{~kg}$ and Control group.

\begin{tabular}{|c|c|c|c|}
\hline INTERVENT] & CONTROL & & \\
\hline $\begin{array}{l}\text { SUBGROUP } \\
\text { mean }(\mathrm{SD})\end{array}$ & $\begin{array}{l}(\mathrm{n}=161) \\
\text { mean }(\mathrm{SD})\end{array}$ & p-value & $95 \% \mathrm{CI}$ \\
\hline
\end{tabular}

\section{SUBGROUP HEALTH CARE COST}

Subgroup: Weight gain $<7 \mathrm{~kg}$

Pregnancy

$\mathrm{n}=51$

Delivery

$1663(528)$

2021(880)

0.05

-715 to -1

2216(932)

$2306(1230) \quad 0.56$

- 392 to 214

Neonatal Care

$3414(5140)$

2927 (4103) 0.47

-841 to 1814

Total Health Care Cost

7987 (8047)

$7255(4804) \quad 0.52$

-1008 to 2471

Subgroup: Weight gain $\geq 7 \mathrm{~kg}$

$\mathrm{n}=92$

Pregnancy

$1719(1037)$

$2021(880) \quad 0.04$

-592 to 13

Delivery

$2503(1045)$

$2306(1030) \quad 0.14$

-62 to 454

Neonatal Care

3057 (4198)

2927(3803) $\quad 0.81$

-902 to 980

Total Health Care Cost

$7278(4803)$

7255 (4804) 0.97

-1174 to 1220

* For the women with singleton pregnancies whose weight was assessed both at the start of the intervention and one to two weeks before delivery.

cases, the results showed no such trend (p-values 0.88 and 0.95 ). There was no difference in costs for the subgroup that gained more than $9.5 \mathrm{~kg}$ when compared to the control group. However, in the subgroup that had a pregnancy weight gain of 4.5$9.5 \mathrm{~kg}$ the mean cost for pregnancy was EURO 574 less $(\mathrm{p}<0.001)$, Table 3.

Intervention sub-groups compared to control sub-groups

Total health care costs between all sub-groups in the intervention and control groups (for example $<7 \mathrm{~kg}$ intervention compared to $<7 \mathrm{~kg}$ control) showed no significant differences. However, differences were found comparing the DRG costs during pregnancy. A statistically significant reduction in costs was found for the intervention 
sub-groups $<7 \mathrm{~kg}$ and $4.5-9.5 \mathrm{~kg}$. Within the other sub-groups a similar trend was found (data not shown).

Table 3. Average costs in EURO per woman or woman/child pair*: Intervention Subgroups and Control groups.

$\begin{array}{llll}\begin{array}{l}\text { INTERVENTION } \\ \text { SUBGROUP } \\ \text { mean (SD) }\end{array} & \begin{array}{l}\text { CONTROL } \\ (\mathrm{n}=161) \\ \text { mean (SD) }\end{array} & \text { p-value } & 95 \% \mathrm{CI}\end{array}$

\section{SUBGROUP HEALTH CARE COST}

Subgroup: Weight gain $<4.5 \mathrm{~kg}$

Pregnancy

$\mathrm{n}=29$

Delivery

1997 (1247)

$1954(1242)$

$2021(880)$

0.92

-491 to 443

2375 (990)

2306 (1029)

0.78

-541 to -404

2307 (926)

0.73

- 319 to 458

Neonatal Care

4300 (8429)

1.0

-390 to -391

Neonatal Care

3055 (4714)

2927 (4103)

0.16

-532 to 3277

Total Health Care Cost

8671(9227)

7255 (4804)

0.88

-1488 to 1744

-751 to 3584

Subgroup: Weight gain $4.5-9.5 \mathrm{~kg} \quad \mathrm{n}=53$

Pregnancy

$1448(845)$

$2021(880)$

$<0.001$

-920 to -227

Delivery

$2343(980)$

2306 (1029)

0.82

-272 to 345

Neonatal Care

$3385(5145)$

2927 (4103)

0.50

-871 to 1785

Total Health Care Cost

7175 (5666)

0.92

-1604 to 144

Subgroup: Weight gain $>9.5 \mathrm{~kg}$

$\mathrm{n}=59$

Pregnancy

1766 (1049)

$2021(880)$

0.11

-569 to 58

Delivery

2453 (1059)

2306 (1029)

0.33

-147 to 442

Neonatal Care

3082 (3971)

2927 (4103)

0.79

-999 to 1309

Total Health Care Cost

7301 (4648)

7255 (4804)

0.95

-1304 to 139

\footnotetext{
* For the women with singleton pregnancies whose weight was assessed both at the
} start of the intervention and one to two weeks before partus. 


\section{Stratified BMI upon admission to the program}

The index women with an initial BMI $30-34.9 \mathrm{~kg} / \mathrm{m}^{2}(\mathrm{n}=100)$ had a mean total healthcare cost - excluding intervention costs - of EURO 7948 while the control women with the same initial BMI $(n=112)$ had a cost of EURO 7023: a non-significant difference $(\mathrm{p}=0.226)$. The index women with an initial BMI $35-39.9 \mathrm{~kg} / \mathrm{m}^{2}(\mathrm{n}=36) \mathrm{had}$ a mean cost of EURO 6136 while the control group with the same initial BMI (n=39) had a cost of EURO 7007: a non-significant difference $(\mathrm{p}=0.249)$. The index women with the highest BMI $(n=19)$ had a mean cost of EURO 8043 while their controls $(\mathrm{n}=21)$ had a mean cost of EURO 8952: also non-significant $(\mathrm{p}=0.723)$. All costs contributing to the total costs(i.e. pregnancy, delivery, neonatal care) were analysed in the same manner. No significant differences were found.

\section{Frequency of exercise}

The attendance to water gymnastics during pregnancy ranged from zero to 28 with a mean of seven and a mode of five. A small negative correlation $(-0.15, \mathrm{p}<0.07)$ between frequency of water gymnastics and gestational weight gain was found; however, no correlation between exercise and costs were found.

\section{Lost weight during pregnancy}

Eleven women lost weight during their pregnancy. No differences were found in costs associated with pregnancy, delivery, neonatal care or total costs when compared to the control group.

\section{Discussion}

This study is, to our knowledge, the first analysis of total costs of an intervention program to limit weight gain in obese women during pregnancy. The cost comparison 
analyses and interpretation of results in the present study were conducted by individuals not connected to the intervention program thereby preventing conflicts of interest. The results show that the intervention program has no economic benefit as a whole, though the intervention group had an approximately EURO 348 reduced cost during pregnancy. Recommendations for obese women's weight gain during pregnancy vary, and are a topic of current debate. The Institute of Medicine (IOM) ${ }^{25}$ has recently changed its recommendation from a minimum weight gain of $6.8 \mathrm{~kg}$ to a current recommendation of weight gain between $5-9 \mathrm{~kg}$, while a study published by Cedergren a suggests that weight gain of less than $6 \mathrm{~kg}$ for obese women is appropriate $^{26}$. The gestational weight gain limits for BMI categories in Cedergren's large population-based cohort study from Swedish Medical Registers showed that a decreased risk of adverse obstetric and neonatal outcomes was associated with lower gestational weight gain than was earlier recommended, especially among obese women. These findings are supported in results of a recent randomized clinical trial concerning the perinatal outcomes in nutritionally monitored obese pregnant women ${ }^{16}$. With regards to the debate concerning recommendations for an obese woman's weight gain during pregnancy, further studies of this issue are warranted to ensure the safety and efficacy of future intervention programs.

The benefits of a reduced cost during pregnancy in this particular intervention study were outweighed by the costs of the intervention (EURO 1616 per participant). During analyses of the data, we found that the pregnancy weight gain that provided the greatest economic saving was between 4.5 and $9.5 \mathrm{~kg}$. Even given the best case scenario under which all women in the intervention group held their weight gain to the interval 4.5 to $9.5 \mathrm{~kg}$, a net loss of roughly EURO 1002 per participant would be expected. Costs of this particular intervention program therefore preclude any 
potential economic benefit. Considering that the motivational meetings and productivity losses due to the meetings contribute $87 \%$ (EURO 1404) of the intervention costs, a sizeable cost reduction here may make cost-effectiveness achievable. Say, for instance, that the motivational meetings could be effectively conducted in groups of six women, every other week as opposed to individual, weekly meetings. The total intervention cost could thus be reduced to roughly EURO 330 per participant. For the women that gain 4.5 to $9.5 \mathrm{~kg}$ a net savings of approximately EURO 249 could be made. Such an adjustment may be warranted for future intervention studies given that roughly half of the women in the intervention group stated that there were too many motivational meetings, and $72 \%$ reported that the social character of the water-gymnastics (a group session) was one of the most positive aspects of the program ${ }^{27}$.

In the intervention study there are both strengths and limitations regarding the methods and sample used. The intervention study was not randomized which can be seen as an important limitation. Randomization is a powerful tool and a good general rule is to randomize whenever possible ${ }^{28,29}$. In all scientific research it is important to control external factors and to make an effort to minimize situational contaminants. The environment has been found to exert a powerful influence on people's emotion and behavior ${ }^{29}$. It requires careful consideration if an intervention- and control group will get treatment and care at the same setting. A continuing intervention program with a new routine might influence the staff to change their behavior and regimens even for those who are supposed to be controls and receive standard care. The antenatal care clinic in Linköping is structured as one large unit. Hence, the intervention program designers were determined to secure that no contamination 
between the intervention and controls would occur and therefore chose to use ACCs in two nearby cities to serve as controls. The antenatal programs in Sweden are standardized and almost identical concerning the management of pregnancy, which ensures similar care at different ACCs. Therefore, the design was a consecutive case control and the designers chose to use two other cities and their antenatal care clinics as controls. Additionaly, background characteristics were analysed in the intervention study to correct for possible confounding factors. However, there may still have been some smaller differences in the management and routines that may have affected the results. The results in the current article are based on univariate statistical analyses. These results may, however, be interpreted to be a reasonable representation of the greater population since the degree of weight gain between the index and control groups was shown to be independent of all demographic characteristics when analyzed by means of ANCOVA ${ }^{22}$.

Of the approximately 110000 children born annually in Sweden ${ }^{30}$, about 11000 are born by obese women ${ }^{4}$. If one-third of those obese women could hold a weight gain within 4.5 to 9.5 kilograms during pregnancy a total direct saving to society of around EURO 1000000 could be expected. With other health benefits that follow from a healthy change in lifestyle, the benefits would certainly exceed this modest short-term savings. Since better health for both woman and child, and a streamlining of budget are natural goals for policy makers and health care providers, further efforts to create a viable weight gain control program during pregnancy intervention are warranted. 


\section{Ethical Approval}

The study was approved by the Human Research Ethics Committee, Faculty of Health Sciences, Linköping University.

\section{Disclosure of interest}

None of the authors have any conflict of interest

\section{Funding}

This study was supported by grants from The Health Research Council in the southeast of Sweden.

\section{References}

1. The Swedish Council on Technology Assessment in Health Care. Fetma problem och åtgärder, En systematisk litteraturöversikt. SBU: Stockholm, Sweden, 2002. (Östman J, Britton M, Jonsson E, eds. Treating and Preventing Obesity. An Evidence Based Review by Weinheim: Wiley-VCH, 2004.)

2. Yeh J, Shelton J A. Increasing pre-pregnancy body mass index: Analysis of trends and contributing variables. Am J Obstet Gynecol. 2005;193:1994-1998.

3. La Coursiere D Y, Bloebaum L, Duncan J D, Varner M W. Population-based trends and correlates of maternal overweight and obesity, Utah 1991-2001. Am J Obstet Gynecol. 2005; 192:832-839.

4. Brynhildsen J, Sydsjö A, Norinder E, Ekholm Selling K, Sydsjö G. Trends in body mass index during early pregnancy in Swedish women 1978-2001. Public Health 2006; 120: 393-399.

5. Dempsey JC, Ashiny Z, Qiu C-F, Miller R S, Sorensen T K, Williams M A. Maternal pre-pregnancy overweight status and obesity as risk factors for caesarean delivery. J Matern Fetal Neonatal Med. 2005;17:179-185. 
6. Sebire NJ, Jolly M, Harris JP, et al. Maternal obesity and pregnancy outcome: a study of 287,213 pregnancies in London. Int J Obes Relat Metab Disord. $2001 ; 25: 1175-82$.

7. Kumari AS. Pregnancy outcome in women with morbid obesity. Int $J$ Gynaecol Obstet. 2001;73:101-7.

8. Baeten JM, Bukasi EA, Lambe M. Pregnancy complications and outcomes among overweight and obese nulliparous women. Am J Public Health. 2001 Mar;91(3):436-40.

9. Vahratian A, Zhang J, Troendle JF, Savitz DA, Siega-Riz AM. Maternal prepregnancy overweight and obesity and the pattern of labor progression in term nulliparous women. Obstet Gynecol. 2004;104:943-51.

10. Cedergren M I. Maternal Morbid Obesity and the Risk of Adverse Pregnancy Outcome. Obstet Gynecol. 2004;103: 219-24.

11. Cedergren, MI, Källén BAJ. Maternal Obesity and Infant Heart Defects. Obes Res. 2003; 11:1065-1071.

12. Kristensen J, Vestergaard M, Wisborg K, Kesmodel U, Secher NJ. Prepregnancy weight and the risk of stillbirth and neonatal death. BJOG. $2005 ; 112: 403-8$

13. Stephansson O, Dickman PW, Johansson A, Cnattingius S. Maternal weight, pregnancy weight gain, and the risk of antepartum stillbirth.Am J Obstet Gynecol. 2001 Feb;184:463-9.

14. Cnattingius S, Bergström R, Lipworth L, Kramer MS. Prepregnancy weight and the risk of adverse pregnancy outcomes. N Engl J Med. 1998 ;338:191-2.

15. Cedergren M. Effects of gestational weight gain and body mass index on obstetric outcome in Sweden. Int J Gynaecol Obstet. 2006;93:269-74. 
16. Thorton YS, Smarkola C, Kopacz SM, Ishoof SB. Perinatal outcomes in nutritionally monitored obese pregnant women: a randomised clinical trial. $J$ Natl Med Assoc. 2009;101:569-577.

17. Crane JMG, White J, Murphy P, Burrage L, Hutchens D. The effect of gestational weight gain by body mass index on maternal and neonatal outcomes. J Obstet Gynaecol Can 2009;31(1):28-35.

18. Chu SY, Bachman DJ, Callaghan WM, Whitlock EP, Dietz PM, Berg CJ, et al. Association between obesity during pregnancy and increased use of health care. N Engl J Med. 2008;358:1444-53.

19. Polley BA, Wing RR, Sims CJ. Randomized controlled trial to prevent excessive weight gain in pregnant women. Int J Obes Relat Metab Disord. 2002;26:1494-502

20. Olson CM, Strawderman MS, Reed RG. Efficacy of an intervention to prevent excessive gestational weight gain. Am J Obstet Gynecol. 2004; 191:530-6.

21. Gray-Donald K, Robinson E, Collier A, David K, Renaud L, Rodrigues S. Intervening to reduce weight gain in pregnancy and gestational diabetes mellitus in Cree communities: an evaluation. CMAJ. 2000;163:1247-51.

22. Claesson I-M, Sydsjö G, Brynhildsen J, et al. Weight gain restriction for obese pregnant women: A case-control intervention study. BJOG 2008; 115:44-50. Epub 2007 Oct 25.

23. Statistics Sweden. http://www.scb.se/templates/tableOrChart 149077.asp (accessed 2006-11-07)

24. Nord DRG Users’ Manual: updated 2004-03-05 http://norddrg.kuntaliitto.fi/manual_2004_Eng_Full (accessed 2006-11-03) 
25. Institute of Medicine. Weight Gain During Pregnancy: Reexamining the Guidelines. Washington, DC: The National Academies Press. Posted online May 28, 2009. (accessed 2010-04-21)

26. Cedergren MI. Optimal gestational weight gain for body mass index categories. Obstet.Gynecol. 2007; 110:459-64.

27. Claesson IM, Josefsson A, Cedergren M, et al. Consumer satisfaction with a weight-gain intervention programme for obese pregnant women. Midwifery. 2008 ;24:163-7. 27. The National Board of Health and Welfare, Sweden. http://www.socialstyrelsen.se/Statistik/statistikdatabas/index.htm (accessed 2006-11-09).

28. Graziano AM, Raulin ML. Research methods : a process of inquiry (with student CD-ROM). Boston, Mass. [u.a.]: Pearson; 2004.

29. Polit DF, Hungler BP. Nursing research : principles and methods. Philadelphia: Lippincott; 1991.

30. Statistics Sweden. Live births in the country 2009. www.ssd.scb.se (accessed 2010-04-28). 